\title{
Bilinguismo como potencial proteção contra o declínio da memória de trabalho no envelhecimento
}

Bilingualism as a potential protection against age-related working memory decline

\section{Johanna Dagort Billig}

Universidade Federal de Ciências da Saúde de Porto Alegre - UFCSPA - Porto Alegre - RS - Brasil

\section{Ingrid Finger}

Universidade Federal do Rio Grande do Sul - UFRGS - Porto Alegre - RS - Brasil

\begin{abstract}
Resumo: A hipótese de uma experiência bilíngue impactar no desempenho de crianças é motivo de escrutínio na literatura há bastante tempo. Porém, foi só mais recentemente que se passou a investigar o impacto dessa experiência na vida adulta e no envelhecimento. Evidências do bilinguismo como uma espécie de proteção contra o declínio cognitivo no envelhecimento têm sido recebidas com entusiasmo, uma vez que o envelhecimento é o principal fator de risco para síndromes demenciais. O presente estudo buscou investigar a extensão do impacto do bilinguismo na memória de trabalho de idosos e adultos. Para tanto, investigou-se o desempenho de 136 participantes bilíngues e monolíngues na tarefa $N$-back. Os resultados revelaram que bilíngues e monolíngues se comportaram de maneira similar em termos de acurácia, mas os idosos bilíngues foram mais rápidos do que os idosos monolíngues na resolução das tarefas, o que revela menores custos cognitivos para os bilíngues. Além disso, a magnitude da diferença do desempenho entre adultos e idosos em termos de tempo de reação foi menor entre os bilíngues, sugerindo que o bilinguismo esteja atuando como reserva cognitiva, retardando o impacto do envelhecimento.
\end{abstract}

Palavras-chave: Bilinguismo. Memória de trabalho. Envelhecimento.

Abstract: The hypothesis that bilingualism can impact on the performance of children has been under great scrutiny for a long time. However, it has been only recently that the impact of this experience has been researched throughout life and aging. Evidence of bilingualism as some kind of protection against age-related cognitive decline has been received with great enthusiasm, as aging is the main risk factor for dementia syndromes. The present study investigated the extension of bilingualism impact on the working memory of adults and older adults. Therefore, we analysed the performance of 136 bilinguals and monolinguals on the $\mathrm{N}$-back task. Our results revealed that bilinguals and monolinguals behaved similarly in terms of accuracy. However, older bilinguals were faster than older monolinguals, which means lower cognitive costs for bilinguals. Moreover, the magnitude of the difference between older bilinguals and younger bilinguals regarding reaction time was lower than for monolinguals, which suggests that bilingualism is acting as a cognitive reserve and delaying age-related cognitive decline.

Keywords: Bilingualism. Working memory. Aging. 


\section{Introdução}

A possibilidade de uma experiência de linguagem bilíngue/multilíngue alterar o desempenho linguístico e cognitivo das crianças tem sido investigada há bastante tempo. Na década de 60, por exemplo, Macnamara (1966) realizou uma espécie de metanálise de estudos realizados entre 1918 e 1962, concluindo que uma experiência bilíngue teria um efeito negativo em termos linguísticos, principalmente no que se refere ao tamanho do vocabulário das crianças. Por outro lado, ainda na década de 60, Peal e Lambert (1962) analisaram o desempenho de crianças em testes de inteligência verbal e não verbal, observando um desempenho superior das crianças bilíngues em comparação com as crianças monolíngues em todos os testes de inteligência. Porém, foi somente mais recentemente que se passou a discutir a possibilidade de uma experiência bilíngue/multilíngue atuar como diferencial no desempenho de adultos e idosos (BIALYSTOK, 2004; BIALYSTOK ET AL., 2007; CRAIK ET AL., 2010; PERQUIN ET AL., 2013), revelando um efeito mais prolongado e permanente dessa experiência de linguagem.

Evidências de estudos psicolinguísticos (BRYSBAERT; VAN DYCK; VAN DE POEL, 1999; COSTA; MIOZZO; CARAMAZZA, 1999; COLOMÉ, 2001) revelam que, para os indivíduos bilíngues, ambas as línguas estão ativas no processamento linguístico. Por isso, a hipótese levantada pelos pesquisadores (GREEN, 1998; BIALYSTOK, MARTIN E VISWANATHAN, 2005) para explicar possíveis benefícios do bilinguismo na infância e no envelhecimento está relacionada com a suposta necessidade de um mecanismo cognitivo que controle a produção linguística e previna possíveis interferências da língua que não está sendo usada no momento. Achados na área de neurociência (RODRIGUEZ-FORNELLS et al., 2006; ABUTELABI, GREEN, 2007) reforçam a hipótese de que o mecanismo de controle cognitivo utilizado pelos indivíduos bilíngues no processamento linguístico seria o mecanismo de controle inibitório, um dos componentes das funções executivas, que são um conjunto de habilidades cognitivas responsáveis pelo controle geral do comportamento. Apesar de a hipótese principal do impacto do bilinguismo estar centrada na estimulação do controle inibitório, há algumas evidências de que esse impacto possa ser mais extenso, atingindo outros componentes das funções executivas, como a memória de trabalho, foco do presente estudo.

O exercício extra em termos de controle inibitório e possivelmente outros mecanismos executivos contribuiria para uma aceleração do desenvolvimento desses mecanismos na infância e no envelhecimento, o que contribuiria para uma desaceleração do declínio desses mesmos mecanismos. Mais especificamente, com relação ao envelhecimento, esse efeito prolongado do bilinguismo/multilinguismo estaria presente na forma de uma espécie de reserva cognitiva, que ajudaria o cérebro bilíngue/multilíngue a lidar melhor com a neurodegeneração associada ao envelhecimento, podendo até retardar os primeiros sintomas clínicos de demência (BIALYSTOK et al., 2007; CRAIK et al., 2010).

É justamente essa possibilidade de uma experiência de linguagem bilíngue/multilíngue atuar como uma espécie de "freio" para o declínio cognitivo natural do envelhecimento que tem empolgado pesquisadores atualmente, uma vez que é crescente o contingente de idosos ao redor do mundo e a longevidade implica em uma maior probabilidade de se viver com doenças crônicas e incapacitantes, tais como as síndromes demenciais. De acordo com a Organização Mundial de Saúde (OMS), estima-se que até 2030 teremos cerca de 65,7 milhões de pessoas com algum tipo de demência e, até 2050, serão 115,4 milhões de pessoas. Relatórios de 2010 do World Alzheimer's Report já apontavam gastos anuais com demências equivalentes a US\$ 604 bilhões de dólares.

Considerando a importância de se melhor entender mecanismos que possam retardar o declínio cognitivo na iminência de uma epidemia de demência, o presente estudo teve como objetivo verificar a extensão do impacto de uma experiência prolongada 
de bilinguismo em uma tarefa de memória de trabalho e a possibilidade de esse impacto ser suficiente para atenuar efeitos de envelhecimento. É importante ressaltar que, para melhor compreender o real impacto do bilinguismo na cognição geral, é preciso considerar variáveis que possam interferir em testes cognitivos, tais como o nível socioeconômico e a capacidade funcional dos participantes. Uma vez que a maioria dos estudos do impacto do bilinguismo na cognição geral não obteve informações sobre o nível socioeconômico e a capacidade funcional dos participantes, nosso estudo vem a contribuir com a literatura ao parear os participantes bilíngues e monolíngues nesses quesitos.

\section{Revisão de literatura}

Conforme Baddeley e Hitch (1974), a memória de trabalho abarcaria três componentes: a alça fonológica (mais próximo do conceito de armazenamento de curto prazo), o esboço visuoespacial e o executivo central. Segundo os autores, a alça fonológica e o esboço visuoespacial seriam sistemas escravos especializados na gravação de diferentes tipos de informações e utilizados pelo executivo central para propósitos específicos. Portanto, o principal componente da memória de trabalho seria o executivo central, que teria a função de selecionar e manipular as informações dos outros dois componentes. Baddeley (2003) afirma que esse modelo parte do princípio de que todos os componentes da memória de trabalho sejam de capacidade limitada e de extrema importância às atividades de raciocínio, aprendizagem e compreensão. Mais recentemente, Baddeley (2000) propôs outro componente para o sistema de memória de trabalho, que chamou de buffer episódico (episodic buffer). Esse mecanismo seria capaz de reter temporariamente informações multidimensionais e, portanto, serviria de conexão entre os demais componentes, a saber, a memória de longo prazo e a percepção.

Dentro dessa perspectiva, há uma distinção entre tarefas que enfatizam o armazenamento/manutenção das informações e as tarefas que também envolvem processamento dessas informações (executivo central). Conforme ReuterLorenz e Sylvester (2004), as tarefas com ênfase no armazenamento ou na manutenção de informações são medidas de memória de curto prazo e as tarefas que também envolvem processamento são medidas de memória de trabalho. Malloy-Diniz et al. (2010) citam as tarefas de repetições de dígitos da escala WAIS-III (análise da alça fonológica) e a tarefa dos Blocos de Corsi (alça visuoespacial) como exemplos de tarefas de armazenamento ou manutenção de informações. Já como exemplo de tarefas que demandariam armazenamento e também manipulação (processamento) de informações, os autores sugerem - PASAT - Paced Auditory Serial Addition Test (GRONWALL, 1977), os trigramas consonantais (STRAUSS, SHERMAN, SPREEN, 2006) e a Sequência de Números e Letras do WAIS (NASCIMENTO, 2000). Segundo Gazzaniga et al. (2006), a tarefa $N$-back é outro exemplo de tarefa que envolve tanto manutenção quanto a manipulação de informação, uma vez que exige do participante não só a manutenção da representação dos itens em mente, como também a atualização constantemente dessa representação na memória de trabalho. Foi por essa razão e pela possibilidade de avaliarmos tempo de reação que optamos pela tarefa $\mathrm{N}$-back no presente estudo.

Estudos têm revelado que um dos processos cognitivos afetados pelo envelhecimento é a memória de trabalho (BOPP, VERHAEGHEN, 2005; SCHMIEDEK et al., 2009). O declínio dos processos de atenção seletiva e controle inibitório estão entre as possíveis justificativas para o desempenho inferior dos idosos nas pesquisas que avaliam a capacidade da memória de trabalho (HASHER, ZACKS, 1988; GAZZALEY et al., 2005). Por exemplo, há evidências de que os idosos são mais vulneráveis à interferência de distratores (WEST, 1999) e menos capazes de ignorar texto irrelevante (CONNELLY et al., 1991).

No que se refere ao bilinguismo, embora a maioria dos estudos tenha investigado a hipótese principal de que uma experiência bilíngue de 
linguagem possa afetar o desempenho dos participantes em termos de controle inibitório, há alguns estudos que analisam o impacto do bilinguismo na memória de trabalho. Para Bialystok e colaboradores (2008), é razoável pensar que uma vantagem bilíngue se generalize do controle inibitório para a capacidade de memória de trabalho, pois a memória de trabalho costuma ser considerada um componente das funções executivas e o controle inibitório tem um papel importante no funcionamento da memória de trabalho (HASHER, ZACKS, 1988; ZACKS, HASHER, 1994). Por outro lado, Adesope e colaboradores (2010) defendem que também seria razoável a hipótese de que o gerenciamento de dois sistemas linguísticos poderia gerar maiores demandas de memória de trabalho e assim prejudicar 0 desempenho dos indivíduos bilíngues/multilíngues.

Bialystok e colaboradores (2004) avaliaram o desempenho de adultos e idosos em três experimentos que envolveram versões da Tarefa de Simon. Embora a Tarefa de Simon seja comumente utilizada para avaliar controle inibitório, os pesquisadores manipularam alguns estímulos nesse estudo e associaram algumas dessas manipulações com uma maior demanda de memória de trabalho. No primeiro experimento $(n=40)$, os participantes responderam a 28 estímulos congruentes e incongruentes e os indivíduos bilíngues obtiveram um efeito Simon menor, além de apresentarem um aumento do efeito Simon relacionado com a idade menor do que os monolíngues. No segundo experimento $(n=94)$, o número de estímulos experimentais aumentou para 192 e outras condições (centro-4, lado- 4) foram incluídas no teste para verificar se a vantagem bilíngue residia na capacidade de ignorar o estímulo irrelevante ou na capacidade de lembrar as regras associadas às cores (capacidade de memória de trabalho). Na condição centro-4, quatro cores foram associadas às duas teclas do computador, o que aumentou o nível de exigência da memória de trabalho. Já na condição lado-4, essas quatro cores foram associadas às duas teclas e os quadrados coloridos apareciam à esquerda ou à direita da tela do computador. Os resultados revelaram que os custos para inibir a resposta irrelevante e para a memória de trabalho foram mais altos para os monolíngues do que para os bilíngues. Além disso, o aumento do tempo de reação associado à idade foi maior para os monolíngues do que para os bilíngues. Finalmente, no terceiro experimento, os participantes $(n=20)$ foram testados em blocos (de 24 testes cada) divididos em duas condições: lado-2 (exigindo processos inibitórios) e centro-4 (exigindo MT). Nesse experimento, o grupo bilíngue manteve 0 mesmo desempenho nos dez blocos. No entanto, o grupo monolíngue melhorou seu desempenho, se equiparando ao grupo bilíngue de forma gradual.

Numa tentativa de compreender melhor a extensão do impacto do bilinguismo na cognição, Bialystok e colaboradores (2008) investigaram o impacto da experiência de linguagem em adultos e idosos em termos de memória de trabalho, acesso lexical e controle inibitório. Para tanto, os pesquisadores investigaram o desempenho de 48 jovens adultos (24 monolíngues e 24 bilíngues) em comparação com 48 idosos (24 monolíngues e 24 bilíngues). Detendo-nos aos resultados em termos de memória de trabalho, que nesse caso foi avaliada através da tarefa de Blocos de Corsi (ordem direta e inversa) e da tarefa Self-ordering Pointing, os pesquisadores observaram (a) um efeito negativo do envelhecimento na versão de ordem inversa dos Blocos de Corsi e uma interação entre experiência de linguagem e idade (vantagem bilíngue apenas entre os jovens) nessa tarefa; (b) apenas um efeito negativo do envelhecimento na tarefa de Self-ordering Pointing. Em outras palavras, o bilinguismo não pareceu influenciar o desempenho dos participantes nessa tarefa de memória de trabalho.

Luo e colaboradores (2013) investigaram o impacto do bilinguismo e do envelhecimento no desempenho de 157 jovens adultos (58 monolíngues e 99 bilíngues) e 121 idosos (61 monolíngues e 60 bilíngues). Buscando investigar os efeitos do tipo de tarefa de memória de trabalho, os pesquisadores selecionaram duas tarefas verbais (alpha span; word span) e uma espacial (blocos de Corsi). A análise dos resultados de ambos os tipos de tarefas revelou um efeito negativo do envelhecimento que, no entanto, foi 
mais pronunciado na tarefa espacial. No que diz respeito ao bilinguismo, os indivíduos bilíngues tiveram um pior desempenho do que seus pares monolíngues nas tarefas verbais e um melhor desempenho nas tarefas espaciais.

Mais recentemente, Bialystok e colaboradores (2014) investigaram os efeitos do bilinguismo e do envelhecimento em adultos e idosos em dois estudos. No primeiro estudo, o foco foi investigar o desempenho dos 130 participantes em termos de controle inibitório. Já o segundo estudo investigou o desempenho de 108 participantes em termos de memória de trabalho fazendo uso de uma versão verbal e de uma versão não-verbal da tarefa recent-probe (JONIDES, NEE, 2006). Na tarefa verbal, o participante precisava identificar se a letra que aparecia na tela havia aparecido anteriormente em uma tela que possuía um conjunto de 5 letras. Na tarefa não-verbal, o participante precisava identificar se a figura de um boneco palito havia aparecido em uma tela anterior que continha 5 imagens de bonecos palitos. Os resultados deste segundo estudo revelaram um melhor desempenho dos participantes bilíngues na tarefa nãoverbal, além de uma diferença maior entre o desempenho de bilíngues e monolíngues entre os idosos.

As pesquisas apresentadas aqui parecem indicar uma desvantagem bilíngue nas tarefas de memória de trabalho verbais (LUO et al., 2013). Entretanto, há indícios de uma vantagem bilíngue em tarefas de memória de trabalho espaciais ou nãoverbais (BYALYSTOK et al., 2004; LUO et al., 2013; BIALYSTOK et al. 2014).

Dessa forma, considerando que a tarefa de memória de trabalho empregada neste estudo ( $N$ back) envolveria um maior custo de controle cognitivo, nossa expectativa era de que o bilinguismo pudesse afetar positivamente o desempenho dos participantes. Nossa expectativa também era de que uma vantagem bilíngue se manifestaria através de uma maior preservação da memória de trabalho entre os idosos bilíngues, manifestada através de menor tempo de reação em comparação com os idosos monolíngues.

\section{Método}

\subsection{Participantes}

Após cálculo amostral (software G Power), verificamos a necessidade de recrutarmos quatro grupos de 34 participantes para investigarmos os efeitos do bilinguismo e do envelhecimento em uma tarefa de memória de trabalho. No total, recrutamos 136 participantes, sendo 68 (34 adultos e 34 idosos) indivíduos monolíngues falantes de português e 68 (34 adultos e 34 idosos) bilíngues falantes de português e hunsrückisch. Consideramos bilíngues aqueles indivíduos capazes de fazer uso de duas línguas dentro de suas necessidades e demanda sociocultural (GROSJEAN, 1989 apud BIALYSTOK, 2001). Logo, nossos participantes usavam as duas línguas em diferentes níveis de frequência. Para garantir possíveis efeitos de experiência na cognição geral, tivemos o cuidado de incluir apenas os participantes que adquiriram ambas as línguas na infância e que usavam cada uma das suas línguas por pelo menos $20 \%$ do seu tempo.

Todos os participantes eram residentes do município de Arroio do Tigre, Rio Grande do Sul, localizado a $250 \mathrm{~km}$ de Porto Alegre. A amostra foi composta na sua maioria por agricultores, faxineiras, donas de casa, comerciantes, costureiras, pedreiros e operadores de máquinas. Nossos participantes frequentaram a escola por no mínimo dois anos e no máximo onze anos. Nenhum desses participantes recebeu instrução escolar em outro idioma que não o português.

\subsection{Instrumentos}

\subsubsection{Entrevista de Histórico de Linguagem, Sociocultural e Estado de Saúde}

Para avaliar a experiência de linguagem foi realizada uma entrevista estruturada com perguntas referentes à aquisição das línguas faladas (idade, ambiente de aquisição), à proficiência (compreensão e produção oral, compreensão e produção escrita) e à 
frequência de uso dessas línguas (tempo de uso ao longo da semana em diferentes atividades sociais). $\mathrm{Na}$ mesma entrevista, também foram feitas perguntas com relação ao estado de saúde dos participantes, mais especificamente, sobre histórico de doenças e uso de medicamentos.

Informações com relação à escolaridade, profissão e renda familiar também foram coletadas nessa entrevista para evitar possíveis efeitos de disparidades socioeconômicas e/ou socioculturais. Aos participantes foi solicitada a assinatura de um Termo de Consentimento Livre e Informado, como condição para a realização dos testes experimentais.

\subsubsection{Perfil de Atividades de Adelaide (PAA)}

Com o objetivo de excluir possíveis interferências de outras variáveis no desempenho dos nossos participantes, incluímos o questionário Perfil de Atividades de Adelaide (Adelaide Activities Profile). Conforme Kanashiro e Yassuda (2011), além dos indicadores capacidade cognitiva, um dos melhores indicadores de saúde do idoso é o de capacidade funcional.

Buscando verificar os tipos de atividades realizadas por idosos e a frequência de realização das mesmas, o Perfil de Atividades de Adelaide (Adelaide Activities Profile) foi elaborado por Clark e Bond (1995) com base no Frenchay Activities Index (SCHULING et al., 1993). Estão incluídos quatro domínios de atividades no questionário de 21 perguntas: serviço doméstico, manutenção do lar, serviço para outros e atividade social. Fizemos uso da versão em português adaptada e validada por Kanashiro e Yassuda (2011) para uma população nipo-brasileira. Nessa versão, os pesquisadores incluíram um domínio chamado por eles de lazer intelectual, no qual incluíram três perguntas referentes a atividades intelectuais e artísticas.

\subsubsection{Teste de Rastreamento}

\subsubsection{Escala de Depressão Geriátrica (EDG)}

Segundo Paradela e colaboradores (2005), a Escala de Depressão Geriátrica (EDG) descrito por Yesavage et al. (1983) é um dos instrumentos de rastreamento de depressão mais utilizado no caso de idosos. Paradela, Lourenço e Veras (2005) afirmam que a EDG tem como vantagem a utilização de perguntas de fácil compreensão e a possibilidade de uma autoaplicação. Fizemos uso da versão longa da escala que continha trinta perguntas na qual os participantes precisavam responder afirmativa ou negativamente a questões relacionadas a como estavam se sentindo na última semana. O participante que obtinha mais de dez respostas depressivas foi deixado de fora da amostra.

A escala foi utilizada para evitar a inclusão de participantes com mais de um terço de respostas depressivas, ou seja, que teriam chances de ter um diagnóstico de depressão, que poderia afetar seu desempenho cognitivo. Oito participantes foram excluídos da amostra por terem somado mais de 10 pontos na EDG. Apesar de ser uma escala voltada para a população idosa, ela também foi aplicada com os adultos, como forma de rastrear possíveis participantes deprimidos.

\subsubsection{Teste Experimental}

\subsubsection{N-back}

A tarefa N-back é comumente utilizada para avaliar memória de trabalho. Nessa tarefa, ao participante é solicitado responder se o item apresentado no momento (número, letra) corresponde a um item apresentado anteriormente. Com diferentes graus de dificuldade esta tarefa pode ser do tipo:

a) 0-Back (controle): o participante precisa verificar se o estímulo apresentado no momento é igual ao primeiro item apresentado na sequência de estímulos;

b) 1-Back: o participante precisa verificar se o estímulo apresentado no momento é igual ao último estímulo apresentado;

c) 2-Back: o participante precisa verificar se o estímulo apresentado no momento é igual ao penúltimo estímulo apresentado. 
Nossa tarefa N-back foi elaborada com 60 estímulos (números entre 1 e 9) em um laptop DELL equipado com o software E-prime 2.0. Os estímulos apareciam na tela do laptop e aos participantes era solicitado que pressionassem uma tecla sinalizada com a palavra SIM se o estímulo fosse igual ao estímulo anterior (2; 2), e uma tecla com a palavra NÃO se o estímulo fosse diferente $(2 ; 3)$. As teclas utilizadas eram do próprio laptop e foram sinalizadas com um adesivo branco ( $\mathrm{SIM}=$ tecla 1 à esquerda; $\mathrm{NA} O=$ tecla 0 à direita). Em 20\% dos casos, a resposta era SIM.

O presente experimento foi apresentado da seguinte forma:

a) apresentação de ponto de fixação (+) por $500 \mathrm{~ms}$;

b) apresentação de estímulo até o participante pressionar uma das teclas de resposta;

c) apresentação de tela branca por $1.000 \mathrm{~ms}$;

d) apresentação de ponto de fixação (+) por $500 \mathrm{~ms}$. uma análise de variância (ANOVA). Para todas as análises foram realizados procedimento de post-hoc de Bonferroni utilizando-se nível de significância de 0,05. Foram excluídos da análise os TRs (tempo de reação) das respostas erradas; assim como TRs inferiores a 250 milissegundos.

\section{Resultados}

Nossa amostra foi composta por 136 participantes, que foram divididos em quatro grupos: jovens monolíngues ( $n=34)$; jovens bilíngues ( $n=34$ ); idosos monolíngues ( $n=34)$ e idosos bilíngues $(n=34)$. Os dados referentes à idade, sexo, escolaridade e funcionalidade (Adelaide) desses participantes são apresentados na Tabela 1. Após análise estatística (ANOVA), não foram encontradas diferenças estatisticamente significativas entre os grupos quanto à distribuição por sexo $(x 2=0,353 ; p=0,95)$.

\section{Tabela 1: Dados sociodemográficos}

\begin{tabular}{|c|c|c|c|c|c|}
\hline & \multicolumn{2}{|c|}{ Jovens } & \multicolumn{2}{|c|}{ Idosos } & \multirow[b]{2}{*}{$F$ ou $X^{2}($ sig) } \\
\hline & $\begin{array}{l}\text { Monolíngues } \\
(\mathrm{N}=\mathbf{3 4})\end{array}$ & $\begin{array}{l}\text { Bilíngues } \\
(\mathbf{N}=\mathbf{3 4})\end{array}$ & $\begin{array}{c}\text { Monolíngues } \\
(\mathrm{N}=\mathbf{3 4})\end{array}$ & $\begin{array}{l}\text { Bilíngues } \\
(\mathbf{N}=\mathbf{3 4})\end{array}$ & \\
\hline Sexo (M/F) & $17 / 17$ & $15 / 19$ & $17 / 17$ & $17 / 17$ & $\begin{array}{c}X^{2}=0,353 \\
(p=0,95)\end{array}$ \\
\hline Idade (M;DP) & $46,56(6,14)^{a}$ & $\begin{array}{c}46,94 \\
(6,93)^{\mathrm{a}}\end{array}$ & $64,56(3,10)^{b}$ & $\begin{array}{c}65,09 \\
(3,61)^{b}\end{array}$ & $\begin{array}{l}F=17,35 \\
(p<0,05)\end{array}$ \\
\hline $\begin{array}{l}\text { Escolaridade } \\
\text { (M;DP) }\end{array}$ & $8,26(2,82)^{a}$ & $8,12(3,02)^{a}$ & $4,85(2,41)^{\mathrm{b}}$ & $5,15(1,95)^{\mathrm{b}}$ & $\begin{array}{c}F=136,39 \\
(p<0,05)\end{array}$ \\
\hline Adelaide (M; DP) & $36,47(9,01)^{a}$ & $\begin{array}{l}38,67 \\
(9,73)^{a}\end{array}$ & $40,24(8,64)^{a}$ & $\begin{array}{c}39,29 \\
(8,67)^{a}\end{array}$ & $\begin{array}{l}F=1,070 \\
(p=0,36)\end{array}$ \\
\hline
\end{tabular}

\section{Nota. Os grupos com a mesma letra representam que não há diferença estatisticamente significativa} entre eles pelo post-hoc de Scheffe.

O número de estímulos e o tempo entre as telas foi sugerido pela Professora Lori Altmann do Departamento Speech, Language and Hearing Sciences da Universidade da Flórida, que já havia trabalhado com participantes idosos.

\subsubsection{Análise dos dados}

Foram realizadas estatísticas descritivas e inferenciais, sendo os grupos comparados através de
Os grupos também se mostraram comparáveis em termos de funcionalidade no Perfil de atividades de Adelaide $(F=1,070 ; p=0,36)$. Segundo Kanashiro e Yassuda (2011), a capacidade funcional é um dos melhores indicadores de saúde do idoso (ROYALL et al., 2005). O fato de nossos grupos serem comparáveis em termos de funcionalidade sugere que todos os grupos gozavam de um bom nível de saúde e bemestar social, uma vez que há evidências de uma relação entre maior funcionalidade e menor declínio 
(MENEC, 2003). A equiparação dos grupos em termos de funcionalidade sugere também que possíveis diferenças encontradas entre os grupos não acurácia das respostas dos participantes na tarefa. Não foi encontrado nenhum efeito significativo de grupo linguístico ou de idade.

\section{Tabela 2: Tarefa N-back 1

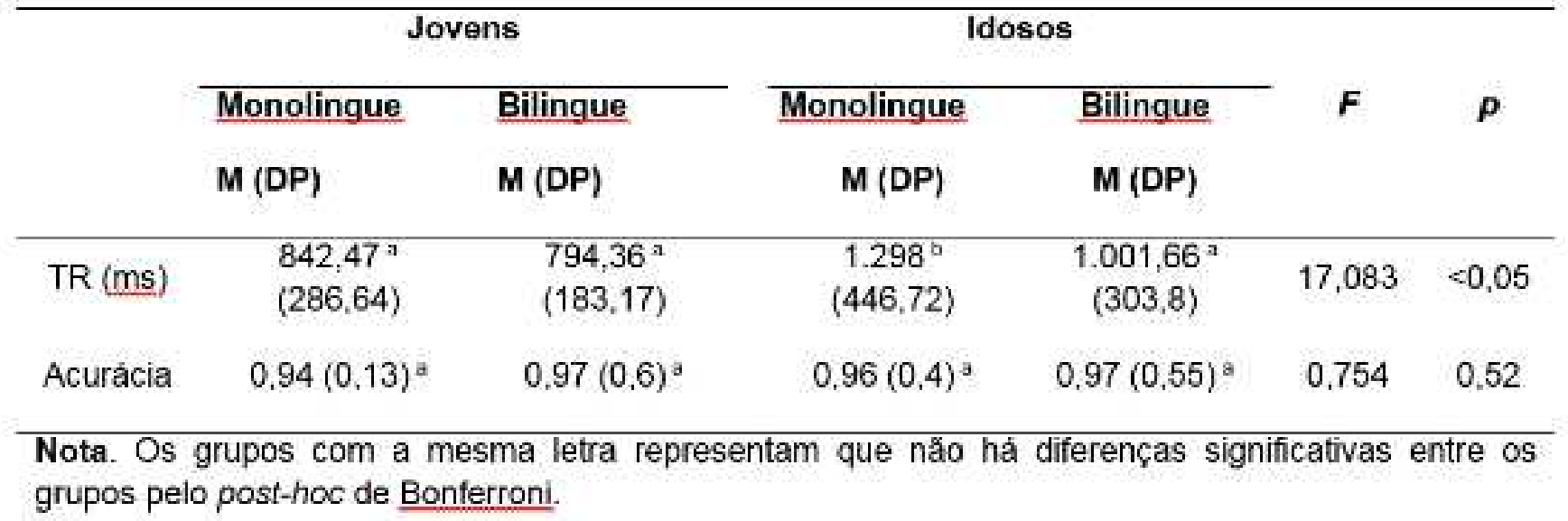

estavam relacionadas a efeitos de algum dos domínios de atividades (atividades intelectuais, por exemplo) investigados no Perfil de Adelaide. É importante deixar claro que a maioria dos estudos que comparam populações bilíngues e monolíngues não faz nenhum tipo de análise da funcionalidade dos participantes, logo é possível que, outros tipos de experiências, além do bilinguismo, possam estar influenciando o desempenho desses participantes.

Por outro lado, nossa análise apontou diferenças significativas entre os grupos em termos de idade $(F=17,35 ; p<0,05)$ e escolaridade $(F=136,39$; $p<0,05)$. Contudo, conforme o post hoc Scheffe, essas diferenças ocorrem exclusivamente entre diferentes grupos etários (jovens versus idosos) e não entre os grupos monolíngues e bilíngues no mesmo. É importante deixar claro que a diferença em termos de escolaridade entre os diferentes grupos etários (jovens versus idosos) já era esperada, uma vez que na época em que o grupo de idosos frequentou o ensino fundamental, não havia escolas no município que oferecessem mais do que os primeiros quatro anos de estudo.

A média e o desvio padrão dos tempos de reação (em milissegundos) e da acurácia de todos os participantes na Tarefa N-Back são apresentadas na Tabela 2. Uma análise de variância (ANOVA) foi empregada para realizar a análise estatística da
Porém, no que se refere ao tempo de reação, a análise revelou uma vantagem significativa dos idosos bilíngues em termos de tempo de reação na comparação com os idosos monolíngues. Além disso, houve uma interação entre grupo linguístico e idade, sendo que os idosos monolíngues foram significativamente mais lentos que os três demais grupos $(F=17,083 ; p<0,05)$. Isso sugere um efeito de idade só entre os monolíngues, já que o grupo de bilíngues idosos se comportou de mesma maneira que ambos os grupos de jovens (monolíngues e bilíngues).

\section{Discussão}

Considerando evidências de uma vantagem bilíngue em tarefas com maior demanda de processamento executivo (BIALYSTOK et al., 2004; BIALYSTOK et al; 2007), esperávamos que os participantes bilíngues respondessem com mais rapidez e acurácia aos estímulos do que os participantes monolíngues. Essa hipótese foi confirmada em parte, pois não houve um efeito de experiência de linguagem entre os jovens, apenas entre os idosos e em termos de tempo de reação.

Apesar de essa vantagem bilíngue ter-se manifestado apenas entre os idosos, esse resultado corrobora evidências anteriores (BIALYSTOK et al., 2004), que apontavam uma vantagem bilíngue em 
tarefas que demandavam maior controle executivo (ordem inversa de span espacial; Tarefa Simon com 4 cores). É possível que tivéssemos observado uma vantagem bilíngue também entre os jovens se tivéssemos optado pela versão $\mathrm{N}$-back 2 , nessa versão, o participante precisa lembrar qual foi o penúltimo número apresentado. Entretanto, como explicamos na seção Método, optamos por deixar a tarefa $\mathrm{N}$-back 2 de fora, pois os participantes demonstraram grande dificuldade e uma acurácia muito baixa na resolução dessa tarefa na testagem piloto.

Outra possível explicação para o fato de que uma vantagem bilíngue não foi encontrada entre os jovens está relacionada ao funcionamento executivo ao longo da vida. Conforme Zelazo et al. (2004), evidências apontam que as funções executivas seguem o movimento de um $\mathrm{U}$ invertido ao longo do desenvolvimento, logo idosos e crianças apresentariam um desempenho inferior ao dos adultos jovens, que estariam no seu pico de eficiência executiva. Considerando esse fato, é provável que diferenças significativas só venham a aparecer entre os grupos que não estejam no seu pico de eficiência, ou seja, os idosos. De fato, no estudo de Bialytok et al. (2004), a diferença entre bilíngues e monolíngues foi maior entre os idosos.

Levando em consideração evidências de que o envelhecimento pode trazer prejuízos aos idosos em termos de memória de trabalho (VERHAEGEN, BASAK, 2005; VAN GERVEN et al., 2008), nossa hipótese era de que a magnitude da diferença de desempenho entre os bilíngues jovens e idosos fosse menor do que para os monolíngues. Essa hipótese foi confirmada, já que não houve um impacto significativo do envelhecimento entre os bilíngues. Nosso resultado corrobora os achados anteriores (Bialystok et al., 2004; Bialystok et al., 2014). No estudo de 2004, efeitos significativos de idade apareceram para os monolíngues a partir dos 60 anos, enquanto que para os bilíngues somente a partir dos 70 anos. No caso da nossa amostra, o grupo de idosos tinha entre 60 e 70 anos de idade. Por isso, é possível que tivéssemos achado um efeito de idade entre os bilíngues se tivéssemos incluído participantes com mais de 70 anos na amostra.

Em resumo, o desempenho de nossos participantes na Tarefa $\mathrm{N}$-back 1 sugere que uma experiência bilíngue de linguagem possa contribuir para a atenuação do impacto do envelhecimento na memória de trabalho. Uma vez que a tarefa de memória de trabalho utilizada neste estudo envolvia não só armazenamento de informações, mas também processamento executivo, é possível supor que essa vantagem bilíngue esteja relacionada ao executivo central da memória de trabalho. De acordo com Morales et al. (2013), há uma tendência na literatura de se encarar as funções executivas como habilidades separadas, mas correlacionadas. Dentro dessa perspectiva, a memória de trabalho seria afetada por qualquer experiência que afetasse as funções executivas.

\section{Conclusão}

As evidências aqui encontradas, assim como as evidências encontradas em outros estudos com adultos (BIALYSTOK et al., 2004; BIALYSTOK et al., 2007) e com crianças (MORALES et al., 2013) corroboram a hipótese de que o bilinguismo possa ter um efeito mais amplo no processamento executivo do que simplesmente em termos de controle inibitório. Uma vez que também levamos em consideração variáveis como nível socioeconômico e capacidade funcional, essas evidências reforçam a hipótese de que o bilinguismo possa atuar como uma espécie de reserva cognitiva e desacelerar 0 processo de envelhecimento.

Indiretamente, esses resultados também chamam a atenção para a importância de se reconhecer as inúmeras comunidades bilíngues/multilíngues espalhadas pelo Brasil, na tentativa não só de valorizar a identidade linguística dessas comunidades, mas também na tentativa de promover um envelhecimento mais saudável dessa população. 


\section{Referências}

ABUTALEBI, J.; GREEN, D.W. Bilingual language production: the neurocognition of language representation and control. Journal of Neurolinguistics, v. 20, p. 242-275, 2007.

ADESOPE, O.; LAVIN, T.; THOMPSON, T.; UNGERLEIDER, C. A systematic review and metaanalysis of the cognitive correlates of bilingualism. Review of Educational Research, v. 80, n.2, p. 207$245,2010$.

BADDELEY, A. D. The episodic buffer: a new component of working memory? Trends in Cognitive Sciences, v. 4, n. 11, p. 417-423, 2000.

BADDELEY, A. D. Working memory: looking back and looking forward. Nature reviews: neuroscience, v. 4, p. 829-839, 2003.

BADDELEY, A. D.; HITCH, G. J. Working memory. In: G. A. Bower (ed.) Recent Advances in Learning and motivation, v. 8, p. 47-89, New York: Academic Press, 1974.

BIALYSTOK, E. Bilingualism in Development: language, literacy, \& cognition. Nova lorque: Cambridge University Press, 2001.

BIALYSTOK, E.; CRAIK, F. I.; KLEIN, R.; VISWANATHAN, M. Bilingualism, aging, and cognitive control: Evidence from the Simon task. Psychology and aging, v. 19,p. 290-303, 2004.

BIALYSTOK, E.; CRAIK, F.; FREEDMAN, M. Bilingualism as a protection against the onset of symptoms of dementia. Neuropsychologia, v. 45, p. 459-464, 2007.

BIALYSTOK, E.; CRAIK, F. I.; LUK, G. Cognitive control and lexical access in younger and older bilinguals. Journal of Experimental Psychology: Learning, Memory, and Cognition, v. 34, n. 4, p. 859-873, 2008.

BIALYSTOK, E.; MARTIN, M. M.; VISWANATHAN, M. Bilingualism across the lifespan: the rise and fall of inhibitory control. International Journal of Bilingualism, v. 9, p. 103-119, 2005.

BIALYSTOK, E.; POARCH, G.; LUO, L; CRAIK, F. Effects of bilingualism and aging on executive function and working memory. Psychol Aging, v. 29, n.3, p. 696-705, 2014.

BOPP, K.L.; VERHAEGHEN, P. Aging and verbal memory span: A meta-analysis. Journal of Gerontology: B Series, v. 60(5), p. 223-233, 2005.

BRYSBAERT, M., VAN DYCK, G., \& VAN DE POEL, $M$. Visual word recognition in bilinguals: Evidence from masked phonological priming. Journal of Experimental Psychology: Human Perception and Performance, 25, 137-148, 1999.
CLARK, M. S.; BOND, M. J. The Adelaide Activities Profile: A measure of the lifestyle activities of elderly people. Aging Clinical and Experimental Research, n. 7, v. 4, p.174-184, 1995.

COLOMÉ, A. Lexical activation in bilinguals' speech production: language-specific or languageindependent? Journal of Memory and Language, v. 45, p. 721-736, 2001.

CONNELLY, S. L.; HASHER,L.; ZACKS, R. T. Age and reading: The impact of distraction. Psychology and aging, v. 6, p. 533-541, 1991.

COSTA, A.; MIOZZO, M.; CARAMAZZA, A. Lexical selection in bilinguals: do words in the bilingual's two lexicons compete for selection? Journal of Memory and Language, v. 41, p.365-397, 1999.

CRAIK, F.; BIALYSTOK, E.; FREEDMAN, M. Delaying the onset of Alzheimer disease: bilingualism as a form of cognitive reserve. Neurology, v. 75, p. 17261729, 2010.

GAZZALEY, A.; COONEY, J.W.; RISSMAN, J., D'ESPOSITO, M. Top-down suppression deficit underlies working memory impairment in normal aging. Nat Neurosci, v. 8, p. 1298-300, 2005.

GAZZANIGA, M. S.; IVRY, R.; MANGUN, G. R. Neurociência Cognitiva: a biologia da mente. Porto Alegre: Artmed, 2006.

GREEN, D. W. Mental control of the bilingual lexicosemantic system. Bilingualism: Language and Cognition, v. 1, p. 67-81, 1998.

GRONWALL, D. Paced Auditory Serial Addition Task: A measure of recovery from concussion. Perceptual and Motor Skills, v. 44, p. 367-373, 1977.

GROSJEAN, F. Neurolinguistics, beware! The bilingual is not two monolinguals in one person. Brain and language, v. 36, p. 3-15, 1989.

HASHER, L.; ZACKS, R.T. Working memory, comprehension and aging: a review and new view. In: H. H. Bowerm (ed.), The psychology of learning and motivation. New York: Academic Press; 1988. p. 193-225.

JONIDES, J.; NEE, D. E. Brain mechanisms of proactive interference in working memory. Neuroscience, v. 139, p.181-193, 2006.

KANASHIRO, M. M.; YASSUDA, M. S. Estudo da Adaptação e Aplicabilidade do Questionário Perfil de Atividades de Adelaide em Idosos de uma Comunidade Nipobrasileira. Psicologia: Reflexão e Crítica, n. 24 v. 2, p. 245-253, 2011.

LUO, L.; CRAIK, F.; MORENO, S.; BIALYSTOK, E. Bilingualism interacts with domain in a working memory task: evidence from aging. Psychology and Aging, v. 28, n. 1, p. 28-34, 2013. 
MACNAMARA, J. Bilingualism and primary education. Edinburgh: Edinburgh University Press, 1966.

MALLOY-DINIZ, L.; DE PAULA, J. J.; LOSCHIAVOALVARES, F. Q.; FUENTES, D.; LEITE, W. B. Exame das funções executivas. In: MALLOYDINIZ, L. ET AL. (eds.) Avaliação neuropsicológica. Porto Alegre: Artmed, 2010, p. 94-113.

MENEC, V. The relation between everyday activities and successful aging: A 6-year longitutinal study. Journal of Gerontology B: Psychological Sciences and Social Sciences, n. 58, v. 2, p. 74-82, 2003.

MORALES, J.; CALVO, A.; BIALYSTOK, E. Working memory development in monolingual and bilingual children. J. Exp Child Psychology, v. 114, p. 187202, 2013.

NASCIMENTO, E. D. Adaptação e validação do teste WAIS-III para um contexto brasileiro. Brasília, 2000. Tese (Doutorado) - Universidade de Brasília.

PARADELA, E.M.P.; LOURENÇO, R.A.; VERAS, R.P. Validação da escala de depressão geriátrica em um ambulatório geral. Revista de Saúde Pública, v. 39, n. 6, p. $918-923,2005$

PEAL, E.; LAMBERT, W. E. The relation of bilingualism to intelligence. Psychological Monographs, v. 76, p. 1-23, 1962.

PERQUIN, M.; VAILLANT, M.; SCHULLER, A.; PASTORE, J.; DARTIGUES, J.; LAIR, M.; DIEDERICH, N. Lifelong exposure to multilingualism: new evidence to support cognitive reserve hypothesis. PLOS One, v. 8, p. 1-7, 2013.

REUTER-LORENZ, P.; SYLVESTER, C. C. The cognitive neuroscience of working memory and aging. In: CABEZA, R.; NYBERG, L.; PARKER, D. Cognitive Neuroscience of Aging: Linking cognitive and cerebral aging. New York: Oxford University Press, 2004, p. 186-217.

RODRIGUEZ-FORNELLS A., DE DIEGO BALAGUER R., MÜNTE T. F. Executive functions in bilingual language processing. Lang. Learn. v. 56, p. 133190, 2006.

ROYALL, D. R.; PALMER, R.; CHIODO, L. K.; POLK, M. J. Executive dysfunction correlates with impaired functional status in older adults with varying degrees of cognitive impairment. International Psychogeriatrics, v. 20, n. 6, p. 1104-15, 2005.
SCHMIEDEK, F.; LI, S.; LINDENBERGER, U. Interference and Facilitation in Spatial Working Memory: Age-Associated Differences in Lure effects in the N-back Paradigm. Psychology and Aging, v. 24, n. 1, p. 203-210, 2009.

SCHULING, J., HAAN, R., LIMBURG, M., GROENIER, $\mathrm{K}$. H. The Frenchay Activities Index: Assessment of functional status in stroke patients. Stroke, 24(8), 1173-1177, 1993.

STRAUSS, E.; SHERMAN, E. M.S.; SPREEN, O. A compendium of neuropsychological tests: Administration, norms, and commentary. Oxford: Oxford University Press, 2006.

VAN GERVEN, P. W.M.; MEIJER, W. A.; PRICKAERTS, J. H. M.; VAN DER VEEN, F. M. Aging and focus switching in working memory: excluding the potential role of memory load. Experimental Aging Research, v. 34, p. 367-378, 2008.

VERHAEGHEN, P., BASAK, C. Aging and switching of the focus of attention in working memory: Results from a modified N-Back task. Quarterly Journal of Experimental Psychology A, v. 58, p. 134-154, 2005.

WEST, R. L. Visual distraction, working memory, and aging. Memory and cognition, n. 27, p. 1064-1072, 1999.

World Alzheimer's Report 2010: the global economic impact of dementia. London: Alzheimer's Disease International, 2010.

World Health Association (WHO). Dementia: a public health priority. Geneva: WHO, 2012.

YESAVAGE, J.A.; BRINK, T. L.; ROSE, T. L.; LUM, O.; HUANG, V.; ADEY, M.; LEIRER, V. O. Development and validation of a geriatric depression screening scale: a preliminary report. J. Psychiatr Res, v. 17, p. 37-42,1983.

ZACKS, R. T.; HASHER, L. Directed ignoring: Inhibitory regulation of working memory. In: DAGENBACH, D.; CARR, T. H. Inhibitory mechanisms in attention, memory and language. San Diego: Academic Press, 1994, p. 241-264.

ZELAZO, P.; CRAIK, F. I. M.; BOOTH, L. Executive function across the life span. Acta Psychologica, v. 115, p. 167-183, 2004.

\section{COMO CITAR ESSE ARTIGO}

BILLIG, Johanna Dagort; FINGER, Ingrid. Bilinguismo como potencial proteção contra o declínio da memória de trabalho no envelhecimento. Signo, Santa Cruz do Sul, v. 41, n. 71, set. 2016. ISSN 1982-2014. Disponível em: <https://online.unisc.br/seer/index.php/signo/article/view/7201>. Acesso em: doi: http://dx.doi.org/10.17058/signo.v41i71.7201. 